\title{
EDITORIAL
}

\section{OCCUPATIONAL SOCIAL WORK AND EMPLOYEE ASSISTANCE PROGRAMMES: CONTRIBUTIONS FROM THE WORLD OF WORK}

Since the inception of the first formal Employee Assistance Programme (EAP) in South Africa in 1986 by the Chamber of Mines of South Africa, as a result of a feasibility study completed in December 1985, there has been enormous growth in this field of specialisation. Services were soon expanded beyond the mining industry and infiltrated sectors such as the financial sector, food sector and motor industry, to name a few. The public sector soon followed, but it was only in 1996 that a formal commitment was made by the Department of Public Service Administration (DPSA) to issue instructions to government departments on national, provincial and local authority levels.

A number of factors contributed to the growing need for research in this field, i.e. the creation of the Employee Assistance Professionals Association of South Africa (EAPA-SA) in the mid1990s, the entrance of service providers into the field and training initiatives by the University of Witwatersrand for the training of occupational social workers and the University of Pretoria for training of EAP practitioners (social workers, psychologists, educators, nurses, chaplains to name a few) on both a short-course level (since 1998) and a master's level (since 2001).

Although research in the beginning years focused strongly on aspects such as needs assessments and the design of the EAP, training and marketing, the focus currently is reflecting on advancement in the field, as the current group of articles testifies.

This special issue offers the reader results from research in the field of occupational social work, which typically covers needs on a preventative level, and of special target groups in the workplace, and deals with conflict management, assertiveness training, experiences of working mothers, personal finance management, bereavement, HIV and AIDS, substance abuse, and stress in the workplace. As far as EAP is concerned, articles address challenging issues such as the rationale, the basic elements and evaluation of EAPs. Because of the dire need for South African data on specifically the evaluation of EAPs, contributions in this edition will certainly strengthen the hand of those practitioners who face the challenging reality of convincing management of the rationale and benefits of EAP services that could be offered to their most important asset.

In the absence of a South African journal dealing specifically with EAPs, the Editorial Board of Social Work/Maatskaplike Werk took the lead in addressing the need for research data through this special edition - a gesture highly appreciated.

Prof Lourie Terblanche, Dr Florinda Taute, Department of Social Work and Criminology, University of Pretoria, Pretoria, South Africa. 